\title{
Singuagens
}

\section{ENSINO DE LÍNGUA PORTUGUESA PARA SURDOS: REVISÃO DOS MÉTODOS E PROPOSTA DE UNIDADE DIDÁTICA PARA O ENSINO DE LEITURA E ESCRITA}

\author{
Fernanda Beatriz Caricari Morais (INES/MEC) \\ Hellen Ferreira (INES/MEC)
}

\begin{abstract}
RESUMO: Neste trabalho, faz-se uma reflexão sobre as abordagens e métodos que influenciam o ensino de Língua Portuguesa aos alunos surdos. A escolha do tema baseia-se nas dificuldades encontradas para o ensino de uma segunda língua a esses alunos e na recomendação dos dispositivos legais acerca dele. Optou-se pela pesquisa de revisão bibliográfica com ênfase qualitativa, pautada no trabalho de autores renomados da área do ensino de segunda língua para surdos. Verificou-se, em linhas gerais, que o ensino baseado no trabalho com gêneros textuais, conforme propõe Ramos (2004), permite maior contextualização e reflexão sobre os usos e funções da língua. Dessa forma, apresenta-se, também, uma proposta de unidade didática sobre o gênero textual receita.
\end{abstract}

PALAVRAS-CHAVE: Língua Portuguesa como Segunda Língua para Surdos. Métodos de EnsinoAprendizagem de Línguas.

ABSTRACT: This paper aims to reflect the main approaches and methods of teaching Portuguese as a Second Language for deaf students. The choice of this theme was based on the difficulties found in the second language teaching process for these learners and the legal recommendation about how to teach deaf. This research was based on bibliographic review, qualitative, according important researchers in the deaf area that work with Portuguese as a Second Language for deaf students. In general, it was found that the teaching based in textual genres, according to Ramos (2004), allows a better contextualization and reflection about the uses and functions of the language. Therefore, it was presented a proposal of didactic unit about recipe.

KEYWORDS: Portuguese Language as a Second Language for Deaf. Methods of teaching-learning.

\section{INTRODUÇÃO}

O presente artigo tem como objetivo identificar as diferentes abordagens linguísticas que norteiam as práticas do ensino de Língua Portuguesa como segunda língua (L2) para surdos. A partir das determinações legais e dos estudos sobre o ensino de Português para surdos, formas de ensinar a língua foram pensadas para atender às necessidades desse grupo. Para conhecê-las, foi realizada pesquisa bibliográfica a fim de comparar as ações de ensino do Português como segunda língua em cada abordagem. No final deste artigo, sugere-se o uso de uma unidade didática como uma metodologia de perspectiva interacionista no ensino de L2 para surdos. 


\section{$\checkmark$ Linguagens}

A opção por esse tema justifica-se pela pertinência das reflexões no âmbito acadêmico acerca de como ensinar o aluno surdo. Sabe-se que o direito à uma educação bilíngue é garantido aos surdos através dos mecanismos legais; o acesso e a aprendizagem de LIBRAS e de Língua Portuguesa na modalidade escrita é o recomendado. Assim, espera-se que o aluno surdo tenha acesso a duas línguas de modo a garantir sua comunicação e expressão.

Embora tal premissa seja verdadeira, é comum nos deparamos com produções escritas de alunos surdos nas quais as dificuldades de registro refletem marcas de uma abordagem de língua que se materializa na aplicação de métodos artificiais e repetitivos, que tratam a língua como código a ser decodificado e reproduzido. Durante anos, temos visto, através de produções escritas desses alunos (ou da resistência deles ao texto escrito), sinais de que os métodos utilizados, em sua grande maioria, os de abordagem estruturalista, não têm contemplado as demandas reais de uso da língua, fazendo com que produzam textos de forma artificial e rudimentar.

Eis que surge a questão: até que ponto tal escrita estigmatizada e denominada a "escrita do surdo" só existe em decorrência de uma abordagem equivocada para o ensino desses aprendizes?

Nesse sentido, cabe refletir sobre a forma como esse ensino instrumental será ministrado, bem como os métodos existentes para garantir que o aluno surdo se aproprie da modalidade escrita do Português, como produtor e receptor. Temos uma questão central: que métodos já existem para ensinar a Língua Portuguesa como L2 aos alunos surdos? E essa questão suscita outras: qual a diferença do ensino de uma L2? Os métodos utilizados são eficazes? Que abordagem de língua norteia tais métodos? Neste trabalho buscaremos caminhos que nos levem à essas reflexões.

A pesquisa bibliográfica foi a opção metodológica adotada, com ênfase qualitativa e alicerçada por documentos oficiais da educação bem como em pesquisadores e teóricos da área do ensino de língua como L2 para surdos, dos quais se destacam Quadros (2006), Salles (2004) e Lodi (2004).

Assim, este artigo trará breves considerações sobre a educação bilíngue e apresentará duas diferentes abordagens do ensino de língua e seus respectivos métodos, a fim de refletir 


\section{S Linguagens}

sobre os resultados por eles apresentados. Apresentar-se-á, também, uma proposta de unidade didática como exemplo para o ensino de gêneros textuais aos alunos surdos.

\section{DA EDUCAÇÃO BILÍNGUE}

Embora o sujeito surdo tenha conquistado, nos últimos anos, o reconhecimento da LIBRAS como meio legal de comunicação, através da Lei 10.436/2002, encontramos ainda alguns entraves quanto ao processo de ensino dos mesmos. Ao garantir que a Língua Brasileira de Sinais (LIBRAS) é o meio de comunicação dos surdos, evidenciou-se também que tal língua não substituirá o Português na modalidade escrita. Assim, o ensino da Língua Portuguesa deverá acontecer numa perspectiva “dialógica, funcional e instrumental”, segundo o Decreto 5.626/2005.

Dentre as principais barreiras de tal mudança, pode-se citar a formação e qualificação dos professores, a criação de escolas bilíngues e a pesquisa de métodos de ensino que garantam o aprendizado da Língua Portuguesa pelo aluno surdo. Refletir sobre a educação bilíngue é necessário para prosseguir nas discussões sobre abordagens e métodos de ensino, pois as indagações "O que e como ensinar?" exigem respostas iniciais à "Quando e onde ensinar?" Segundo Quadros (2006),

\footnotetext{
Educação bilíngue envolve, pelo menos, duas línguas no contexto educacional. As diferentes formas de proporcionar uma educação bilíngue a uma criança em uma escola dependem de decisões político-pedagógicas. Ao optar-se em oferecer uma educação bilíngue, a escola está assumindo uma política linguística em que duas línguas passarão a coexistir no espaço escolar, além disso, também será definido qual será a primeira língua e qual será a segunda língua, bem como as funções que cada língua irá representar no ambiente escolar. (QUADROS, 2006 p.18)
}

Assim, o contexto bilíngue na educação de surdos tem base no ensino de duas línguas: a LIBRAS e a Língua Portuguesa. A LIBRAS é a chamada L1, ou língua materna, visto que ela é o meio natural de comunicação do aluno surdo; através dela ele constrói sua representação do mundo e forma conceitos. A Língua Portuguesa é a chamada L2, ou segunda língua, uma vez que ela é aprendida pelo aluno através da educação escolar sistematizada. Nessa aprendizagem, o aluno deve contar com os referenciais de sua L1 para 


\section{S Linguagens}

construir o conhecimento da outra língua. Dessa forma, no ensino de L2 para surdos, uma afirmativa recorrente é de que o aprendizado da língua materna criará suportes para o aprendizado de uma segunda língua. (QUADROS, 2006, p.33)

Cabe ressaltar que o ensino da L2, no caso dos surdos, se restringe à modalidade escrita. Não é objetivo que o surdo fale português, mas que estabeleça comunicação através da produção escrita e da leitura e que tenha acesso ao conhecimento veiculado pela escrita. $\mathrm{O}$ aluno surdo poderá desenvolver a fala através de tratamentos fonoaudiológicos com profissionais específicos, em outro espaço que não o escolar, quando está for a vontade da família e do aluno.

\section{ABORDAGENS E MÉTODOS}

Inicialmente, cabe esclarecer os conceitos de abordagem e método. Richards \& Rodgers (1986) apud Salles (2004, p.97), definem abordagem como um conjunto de suposições teóricas acerca da natureza da língua, da aprendizagem dela e da aplicabilidade de ambas em contextos pedagógicos. A abordagem descreve a natureza do assunto que vai ser ensinado. Enquanto o método é conceituado pelos mesmos autores como um conjunto de especificações gerais que visa a apresentação ordenada do material linguístico e que segue determinada abordagem. Assim sendo, a abordagem precede o método e define sob qual prisma a intervenção no objeto ocorrerá, não descartando que variados métodos podem surgir de uma mesma abordagem.

O objeto, nesta pesquisa, é a língua, mais precisamente a Língua Portuguesa ensinada aos alunos surdos como L2. Os métodos para o ensino de língua, desenvolvidos nos últimos 60 anos, baseiam-se em três principais abordagens relacionadas a correntes linguísticas: o estruturalismo, o funcionalismo e o interacionismo. Optou-se, neste trabalho, por enfatizar abordagens decorrentes do estruturalismo e do interacionismo a fim de comparar concepções temporalmente afastadas, mas ainda com presença considerável em práticas de ensino dos alunos surdos.

Segundo Salles (2004, p.99), na abordagem estruturalista a língua é concebida como um sistema de elementos estruturalmente relacionados, que precisam ser codificados e 


\section{Linguagens \& Cidadania}

decodificados. Dessa forma, o objetivo de aprendizagem, nessa concepção, é o domínio dos elementos que compõem a língua em níveis fonológicos, gramaticais, de operações gramaticais e lexicais.

Compõem essa abordagem os métodos de ensino baseados na repetição e memorização de sentenças, a realização de exercícios mecânicos e sem uma relação direta com a realidade, com a presença de textos artificiais e trabalhados exclusivamente com a intenção de reforçar os elementos estruturais que se deseja ensinar.

Corroborando com a abordagem estruturalista, Lodi (2004, p.43) discute um modelo com os mesmos princípios. Trata-se do modelo de Processamento Ascendente, no qual a leitura é concebida como um processo de percepção e decodificação e as práticas pedagógicas preveem um trabalho com letras, sílabas, palavras e sentenças isoladas de qualquer contexto. Nesse modelo, o texto é considerado um conjunto de elementos gramaticais e um pretexto para o ensino das regras sintáticas. Como consequência, possibilita que o aprendiz desenvolva um processo automático de decodificação pelo desenvolvimento de um vocabulário de visão.

O Modelo de Processamento Ascendente "foi o que maior deve impacto na educação de surdos, mostrando-se, ainda hoje, atual nas discussões que envolvem o processo de aprendizagem da linguagem escrita por estes sujeitos", afirma Lodi (2004, p.51), visto que o vocabulário visual construído pela criança através desse modelo pode dar uma contribuição para a compreensão do significado da leitura alfabética.

Ainda segundo Salles (2004, p.103), a Abordagem Interacionista, em oposição à estruturalista, trata a língua como meio para as relações pessoais e vê no discurso os exercícios comunicativos essenciais para a construção do conhecimento. Tal abordagem possui duas vertentes teóricas: a) a hipótese da interação, que vê a interação social como facilitador para a aprendizagem, em que as estratégias conversacionais ganham espaço através de reformulações e negociações de significados entre os falantes; b) a teoria sociocultural, na qual a interação é o lugar de aprendizado e, por promover as situações sociais concretas de produção da língua, passa ser o instrumento mediador da construção de conhecimento, qualquer que seja a área ou o assunto. Assim, a autora considera os métodos que se baseiam na Abordagem Interacionista os mais adequados para o ensino que LP como L2 para surdos, 


\section{$\checkmark$ Linguagens}

pois operam com a interação como situação desencadeadora, em que se manifestam a contextualização, a variação, o desempenho comunicativo e os erros, tão necessários para o processo de aprendizagem.

Na linha interacionista, Andrade (2012, p.42) relata sobre a importância do trabalho com diversos gêneros textuais e a ampliação das possibilidades que compreensão e uso da língua que tal trabalho oferece. As práticas de ensino de leitura e escrita de diferentes gêneros, de acordo com ela, devem ser tratadas primeiro em LIBRAS, para que a compreensão ocorra, e depois em Língua Portuguesa, para que a aquisição da L2 também aconteça.

\section{UMA PROPOSTA DE ENSINO DE L2 E A UNIDADE DIDÁTICA}

O ensino de uma L2 requer metodologias e procedimentos específicos para esse fim. No caso do ensino da Língua Portuguesa a um estrangeiro, por exemplo, alguns recursos serão mais explorados e outros não, dependendo da abordagem de língua que norteia essa tarefa. Cabe ressaltar a modalidade da língua ensinada que, no caso de um estrangeiro ouvinte, apesar de ser uma outra língua, é a mesma modalidade de uso de sua própria: a falada.

Quando um aprendiz está diante de uma nova língua como objeto de aprendizagem, tal apropriação pode acontecer de duas maneiras: como língua estrangeira ou como segunda língua. Quando o aprendiz aprende essa outra língua em um espaço onde ela não é a língua oficial, por exemplo, um brasileiro aprendendo inglês no Brasil, onde essa língua não é oficial, ele está diante de uma língua estrangeira. Mas, se o aprendiz for um cidadão brasileiro, que não utiliza a Língua Portuguesa como sua primeira língua, como no caso dos surdos, ao aprendê-la, estará diante de uma L2.

Para o ensino de língua estrangeira já existem propostas metodológicas, como a que se encontra em Ramos (2004). A existência ou não dessas metodologias está também associada ao prestígio que as línguas-alvo possuem na sociedade. Aprender uma língua é adquirir empoderamento cultural, fortalecimento e politização segundo Maher (1996), e favorecer ou não a apropriação de uma língua oficial por grupos minoritários, como os surdos, envolve não 


\section{S Linguagens}

só reflexões pedagógicas acerca de como ensiná-los, mas também políticas, no sentido de com que objetivo os ensinar.

No ensino de L2 para surdos, a presença de línguas de diferentes modalidades exige ações mais assertivas. As demandas de um ouvinte ao aprender uma segunda língua de modalidade oral são diferentes das do surdo ao aprender uma língua na modalidade escrita, visto que sua primeira língua é gestual-visual. Nesse raciocínio, Andrade (2012) afirma:

Considerando que a segunda língua é aprendida de forma sistemática, ou seja, é necessária a utilização de estratégias formais de ensino para que a aprendizagem ocorra, então, o ensino do português para surdos não pode ser realizado da mesma forma que para os ouvintes que são falantes dessa língua. (ANDRADE, 2012, p.37)

$\mathrm{Na}$ abordagem interacionista, encontram-se alguns possíveis caminhos para o ensino da língua não focado nas estruturas gramaticais e sintáticas, mas baseado nas relações estabelecidas entre o aluno e o texto e na construção de sentidos oriundos dele. Salles (2004), baseada em Brown (1994), diz que "uma sala de aula interativa terá uma quantidade razoável de trabalhos em grupos ou pares; fornecimento de situações autênticas em contextos do mundo real; produção visando a uma verdadeira comunicação" entre outras práticas que promovem a reflexão sobre o uso dos gêneros textuais e da língua.

Segundo a autora, a ideia da interação é fundamental para que as situações de uso da língua sejam aproximadas às situações reais de uso da língua, promovendo associações nítidas com o mundo fora da sala de aula. Tal perspectiva é, no contexto da educação de surdos, primordial para que o aprendizado da L2 não seja mecanizado e sem sentido. Nessa proposta, as atividades giram em torno de temas da vida comum, com textos autênticos e relacionados às experiências dos alunos, na qual as produções escritas são destinadas a leitores reais e a construção de conceitos e referências são baseadas na L1 do aluno.

Tomando a proposta de ensino de língua estrangeira apresentada por Ramos (2004) e refletindo sobre sua aplicabilidade no ensino de uma L2 para surdos, conforme Morais (2014), tem-se uma metodologia que permite que o aprendiz surdo reflita sobre os significados e sentidos dos textos que circulam em Língua Portuguesa, bem como interprete e produza textos com maior consciência de suas funções sociais. 


\section{S Linguagens}

Ramos (2004) propõe o trabalho com diferentes gêneros textuais, dialogando com a abordagem interacionista ao considerá-los um recurso pedagógico poderoso porque permitem ao professor refletir sobre os discursos que os alunos precisam compreender e produzir, além de capacitar o professor para entender características desses textos, como seu propósito, contexto de produção e cultura. Nesse sentido, afirma:

\footnotetext{
Em outras palavras, advogo que uma proposta de aplicação de gêneros, diferentemente de outras escolhas de ações instrucionais mais consagradas, como, por exemplo, aquelas que trabalham com o foco exclusivamente no texto, propicia ao professor desenvolver um trabalho em que o uso de textos e questões de conhecimento sistêmico são trabalhados não mais de forma estanque, mas observando-se suas condições e situação de produção. (RAMOS, 2004, p.116)
}

A proposta da autora é dividida em três fases: apresentação, detalhamento e aplicação. A primeira fase objetiva criar condições para que o gênero trabalhado possa ser contextualizado e observado por uma perspectiva mais ampla, explora, ainda, dois outros conceitos: o de conscientização, que promove reflexões sobre local de circulação do gênero, usuários, propósitos; e o de familiarização, que identifica os conhecimentos prévios que o aluno já possui daquele gênero e, se não os possui, disponibiliza acesso às informações sobre o mesmo. Nessa fase, as reflexões têm por base questões do tipo: "Quem escreve esse tipo de texto?", “Para que escreve?", “Qual é o público-alvo?", “ Onde esse texto é veiculado?", dentre outras.

A segunda fase, o detalhamento, aborda aspectos mais específicos e tem como foco a organização retórica dos textos e suas características léxico-gramaticais. Nessa fase, objetivase fornecer condições satisfatórias para compreensão e produção geral dos textos, assim como explorar a função discursiva e os componentes léxicos-gramaticais particulares ao gênero em questão, compreender os significados e a relação entre texto e contexto. Exercícios que abordam comparações de textos do mesmo gênero, identificação dos assuntos principais e percepção de escolhas linguísticas predominantes, compõem essa fase da proposta.

A última fase é a aplicação e é nela que se espera que o aluno consolide sua aprendizagem e se aproprie do gênero em questão. Essa fase tem por objetivo fazer o aluno trabalhar com o gênero como um todo, reintegrando os vários conhecimentos que veio 


\section{Linguagens \& Cidadania}

adquirindo. Ela é composta por duas etapas: a consolidação e a apropriação. Na primeira etapa, expõe-se o aluno a muitos textos do gênero estudado, com o objetivo de retomar a ideia e o conceito através de atividades que visem consolidá-lo. Na segunda, busca-se fazer uma transferência do gênero para a vida real, uma produção efetiva do aluno em situação real de uso do gênero.

\section{ANÁLISE DE DADOS}

Considerando a proposta de Ramos (2004) um caminho possível para o ensino de Língua Portuguesa para surdos, uma vez que se baseia em conhecimentos prévios sobre o universo da leitura e escrita que esses aprendizes possuem, apresentar-se-á a seguir um exemplo de unidade didática baseado no gênero receita. $\mathrm{O}$ exemplo considera como público alvo uma turma do $6^{\circ}$ ano do Ensino Fundamental, composta somente por alunos surdos. A ideia de unidade didática sugere continuidade no estudo de determinado tema, sendo assim, essa proposta contempla, aproximadamente, cinco aulas.

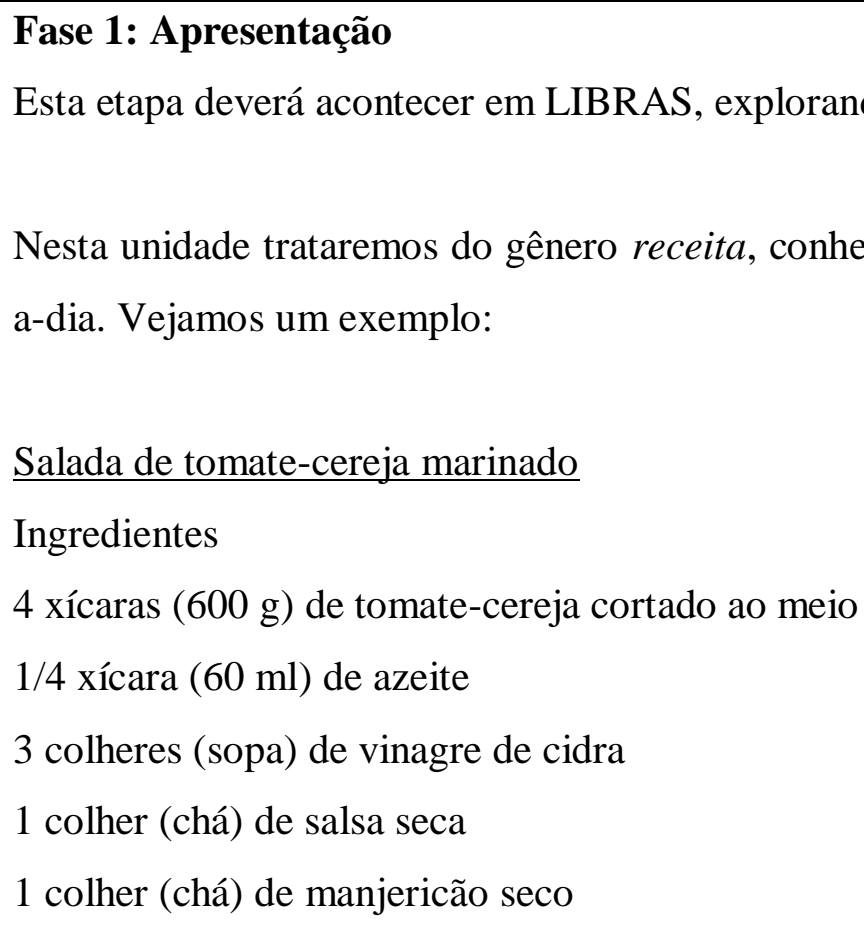
a-dia. Vejamos um exemplo:

$\underline{\text { Salada de tomate-cereja marinado }}$ Ingredientes 4 xícaras $(600 \mathrm{~g})$ de tomate-cereja cortado ao meio $1 / 4$ xícara $(60 \mathrm{ml})$ de azeite 3 colheres (sopa) de vinagre de cidra 1 colher (chá) de salsa seca 1 colher (chá) de manjericão seco

Esta etapa deverá acontecer em LIBRAS, explorando a compreensão do aluno.

Nesta unidade trataremos do gênero receita, conhecido e utilizado por muitas pessoas no dia- 


\section{Linguagens \\ \& Cidadania}

1 colher (chá) de orégano

$1 / 2$ colher (chá) de sal

$11 / 2$ colher (chá) de açúcar

Modo de preparo

1. Em uma tigela pequena ou numa jarra de medida, prepare o molho misturando o azeite, o vinagre de cidra, as ervas, o sal e o açúcar.

2. Coloque o tomate-cereja numa travessa e regue-o com o molho. Misture com cuidado, deixando os tomates cobertos pelo molho. Mantenha a salada na geladeira por 2 horas, no mínimo.

Dica: Antes de servir, misture a salada de baixo para cima.

Preparo: $10 \mathrm{~min}$

Tempo adicional: 2horas na geladeira

Pronto em: 2horas e 10min

Serve: 7 pessoas

Disponível em http://allrecipes.com.br/receita/2948/salada-de-tomate-cereja-marinado.aspx $(02 / 11 / 2016,16: 08)$

Perguntas para reflexão

a) Você já leu uma receita?

b) Para que ela serve?

c) Onde você já viu receitas escritas?

d) Quem costuma ler esse tipo de texto? E essa receita acima? Quem se interessaria por ela?

e) Você conhece alguma outra receita?

f) Na receita acima, você conhece todos os ingredientes usados?

g) Se não conhecer e quiser fazer a receita, como fará para descobrir que ingredientes são?

h) Todas as receitas precisam ir ao forno/fogão? Dê exemplos. 


\section{Linguagens \\ . \& Cidadania}

A fase da apresentação promove uma reflexão sobre o gênero estudado e sobre o reconhecimento do texto em termos de fonte e lugar de circulação, público alvo, propósito comunicativo, conteúdo, contextos de produção e interesses. As atividades propostas nessa fase objetivam sondar os conhecimentos prévios dos alunos sobre o gênero e promover a familiarização com o mesmo. Para isso, espera-se que o professor domine a língua de sinais ou que tenha o auxílio de um intérprete em sala de aula. $\mathrm{O}$ conhecimento prévio do aluno sobre o tema deve ser resgatado através da língua materna do mesmo, por meio de conversa informal, pois foi através dela que ele construiu conceitos e referências, atribuindo significados aos elementos do mundo.

Indagar sobre a aparência do texto, os elementos visuais que o compõe e as hipóteses de função e uso dele, nesse momento, em fase de familiarização, é o recomendado.

\section{Fase 2: Detalhamento}

Esta etapa deverá acontecer primeiramente em LIBRAS, explorando a compreensão do aluno e, no segundo momento, em Português.

Vejamos mais um texto do gênero receita:

BOLO DE CENOURA

INGREDIENTES

MASSA:

- 1/2 xícara (chá) de óleo

- 3 cenouras médias raladas

- 4 ovos

- 2 xícaras (chá) de açúcar

- 2 e $1 / 2$ xícaras (chá) de farinha de trigo

- 1 colher (sopa) de fermento em pó

\section{COBERTURA:}

- 1 colher (sopa) de manteiga

- 3 colheres (sopa) de chocolate em pó 


\section{Linguagens \\ \& Cidadania}

- 1 xícara (chá) de açúcar

MODO DE PREPARO

MASSA:

1. No liquidificador, bata primeiro a cenoura com os ovos e o óleo

2. Acrescente o açúcar e bata por mais 5 minutos

3. Em uma tigela ou na batedeira, adicione o restante dos ingredientes misturando tudo, menos o fermento

4. Acrescente o fermento e misture lentamente com uma colher

5. Asse em forno preaquecido $\left(180^{\circ} \mathrm{C}\right)$ por 40 minutos

\section{COBERTURA:}

1. Misture todos os ingredientes, leve ao fogo e misture até obter uma consistência cremosa.

2. Despeje a calda por cima do bolo.

PREPARO: 40 MIN

RENDIMENTO:8 PORÇÕES

Disponível em http://www.tudogostoso.com.br/receita/23-bolo-de-cenoura.html (02/11/2016, $17: 10)$

a) As receitas têm títulos. Para que eles servem? Qual é o título dessa receita?

b) Em uma receita, temos duas partes principais. Quais partes você observa na receita acima?

c) Compare essa receita com a primeira receita analisada nesta unidade. O que elas têm de semelhante? Marque no quadro abaixo:

\begin{tabular}{||l||l||l||}
\hline & Salada de Tomate-Cereja & Bolo de Cenoura \\
\hline Título & & \\
\hline Lista de ingredientes & & \\
\hline Dicas especiais & & \\
\hline Quantidade de cada ingrediente & & \\
\hline
\end{tabular}




\section{Linguagens \& Cidadania}

\begin{tabular}{||l||l||l||}
\hline Modo de fazer & & \\
\hline Tempo de preparo & & \\
\hline Rendimento & & \\
\hline
\end{tabular}

d) Na parte "Modo de Fazer", das duas receitas, aparecem objetos e utensílios da cozinha. Liste-os:

e) No caso do objeto "travessa", que aparece na primeira receita, que outro sentido essa palavra pode ter, em outra situação? E as palavras "massa" e "cobertura"?

f) No "Modo de Fazer" das duas receitas aparecem verbos, como: bata, acrescente, misture, adicione, asse, prepare, coloque e mantenha. É comum, nas receitas, aparecerem verbos nessa forma. Estes verbos indicam:

( ) um fato que já aconteceu (pretérito perfeito)

( ) um fato que precisa ser feito (imperativo)

( ) um fato que será realizado (futuro do presente)

g) Complete o quadro dando a forma infinitiva dos verbos, como no modelo:

\begin{tabular}{||l||l||}
\hline Bata & Bater \\
\hline Acrescente & \\
\hline \hline Misture & \\
\hline Adicione & \\
\hline Asse & \\
\hline Prepare & \\
\hline Coloque & \\
\hline Mantenha & \\
\hline
\end{tabular}

h) Complete a receita abaixo com os verbos que estão entre parênteses usando a forma imperativa:

Brigadeiro 


\section{Linguagens \\ \& Cidadania}

Ingredientes

Rende: 40 brigadeiros pequenos

- 1 lata de leite condensado

- 1 colher (sopa) de manteiga

- 2 colheres (sopa) de chocolate em pó

- Chocolate granulado para decorar

Modo de preparo

Preparo:1hora Pronto em:1hora

1. que o fundo da panela comece a aparecer. (manter) o fogo médio e

(despejar) o brigadeiro numa superfície untada e ( deixar) esfriar um pouco.

3. Quando o brigadeiro estiver morno, (enrolar) em pequenas bolas e (passar) no chocolate granulado. (colocar) os

brigadeiros em forminhas antes de servir.

Disponível em http://allrecipes.com.br/receita/9542/brigadeiro-f-cil.aspx (20/11/2016, 18:26)

A fase de detalhamento busca aprofundar a compreensão do gênero analisando as características léxico-gramaticais, como as palavras e as estruturas da língua se organizam para atingir o objetivo comunicativo. Segundo Ramos (2004, p. 122), "as atividades farão uso de significados experienciais - processos, escolhas lexicais, etc. -, explorando e entendendo os porquês desses usos e escolhas", dessa forma, refletir sobre a estrutura lexical dos gêneros possibilita uma aprendizagem mais significativa e real, se comparada aos modelos de ensino baseados em exercícios mecânicos de repetição de estruturas.

Nessa fase, o professor vai se dedicar à análise das estruturas do texto junto com os alunos, utilizando os questionamentos da fase anterior para aprofundar as reflexões. Ele deverá usar a LIBRAS para promover a conceituação e explorar a escrita em Língua 


\section{$\checkmark$ Linguagens}

Portuguesa. Deve identificar palavras desconhecidas pelos alunos, buscar significados, expor outros contextos de uso de certos vocábulos e sua mudança de sentido, enfatizar a repetição de determinadas estruturas características daquele gênero, além de incluir novos conceitos.

\section{Fase 3: Aplicação}

Nesta etapa, a prioridade é o registro escrito e a produção escrita individual do gênero proposto.

1. Pesquisar uma receita de sua preferência e trazê-la para sala de aula. Identificar suas partes, colorindo de diferentes cores, cada uma delas. Circular os verbos que estão no modo imperativo. (O trabalho poderá ser feito em grupo e utilizando o tempo da aula na sala de informática.) Haverá exposição dos trabalhos.

2. Escolha um prato que você sabe fazer. Pode ser bem simples, como um suco, om doce, uma salada, o que desejar. Escreva a receita completa.

3. Será organizado um livro de receitas da turma com o trabalho de cada aluno.

Na última fase, a proposta de produção é a culminância do processo, visto que, durante as outras etapas, já foram oferecidos recursos para refletir e analisar o gênero estudado. Nessa fase pretende-se que o aluno consolide os conhecimentos sobre o gênero e se aproprie das ferramentas para produzir textos autonomamente. Cabe ao professor refletir, também, sobre a finalidade da produção, que deve corresponder a uma situação real de uso daquele gênero.

\section{CONSIDERAÇÕES FINAIS}

Por meio dessa pesquisa, objetivou-se refletir sobre as bases metodológicas para o ensino de Língua Portuguesa para alunos surdos. Ao retomarmos o problema de pesquisa, apresentado inicialmente, nota-se que a abordagem de língua que norteou (e talvez norteie) as 


\section{Linguagens \& Cidadania}

práticas de ensino de L2 aos surdos, ainda tem muitas características estruturalistas. Exercícios de repetição de estruturas, classificação e nomeação de componentes sintáticos, treinos ortográficos, muitas são as opções para que esse modelo de ensino se perpetue. A compreensão do texto e sua função não têm lugar de destaque. Espera-se que o aluno surdo produza textos com estruturas perfeitas e com finalidade esgotada no próprio ato da produção. Até que ponto tal escrita estigmatizada e denominada a "escrita do surdo" só existe em decorrência de uma abordagem equivocada para o ensino desses aprendizes?

O ensino de Língua Portuguesa como L2 para surdos não pode acontecer da mesma forma que acontece com os alunos ouvintes. Aprender uma segunda língua exige métodos específicos que objetivam promover autonomia na produção e instrumentalidade no processo de compreensão. Dessa forma, encontra-se na abordagem interacionista da língua, bases para promover práticas fundadas na utilização situações reais de leitura e escrita, bem como nas interações permeadas pelos textos e adequadas aos contextos. Tal quadro possibilita uma aprendizagem mais significativa e não apenas o estudo isolado das estruturas gramaticais e sintáticas. Sobretudo, revestem de sentido e função os textos outrora usados apenas como aglomerado de estruturas.

Encontrou-se, na proposta de Ramos (2004), embora originalmente um modelo oriundo do ensino de língua estrangeira, uma metodologia para o ensino de L2 ao aluno surdo que se fundamenta na linha interacionista, partindo do texto para seus componentes, e não o contrário, como comumente acontece. A proposta de trabalho com gêneros textuais através da unidade didática atende o que está recomendado no Decreto 5.626/2005, sendo um processo de ensino "dialógico, funcional e instrumental", ao passo que promove a interação e a exposição de conhecimentos prévios dos alunos, reflete sobre os usos reais dos textos na sociedade e propõe o estudo dos componentes estruturais da língua de maneira contextualizada.

Embora se possa obter resultados consistentes com o emprego dessa proposta, é sabido que existem ainda questões que precisam de atenção. Dentre tantas, como a formação do professor para atuar em contextos bilíngues, as mudanças necessárias nas formas de avaliação, a produção de material didático que atenda às especificidades do alunado surdo, destaca-se, no âmbito dessa pesquisa, o debate sobre o que é dominar uma segunda língua. 


\section{S Linguagens}

Além da mudança de abordagem de língua e, consequentemente, dos métodos de ensino que dela provem, há de se determinar o grau de domínio esperado. A incompatibilidade entre o que se ensina e o que se deseja ver aprendido parece ser o maior problema ao pensarmos o ensino de L2 para surdos. Propõe-se, assim, a continuação deste estudo com foco na avaliação da aprendizagem de LP como segunda língua.

\section{REFERÊNCIAS}

ANDRADE, M. M. F. de. Práticas De Ensino Da Língua Portuguesa Para Alunos Surdos. Dissertação (Mestrado em Educação) - Universidade Metodista de Piracicaba, São Paulo, 2012.

BRASIL. Decreto $N^{\circ}$ 5.626. Regulamenta a Lei $n^{\circ} 10.436$, de 24 de abril de 2002, que dispõe sobre a Língua Brasileira de Sinais-LIBRAS, e o art.18 da Lei n ${ }^{\circ} 10.098$, de 19 de dezembro de 2000. Publicado no Diário Oficial da União em 22/12/2005.

LEI N¹0.436. Dispõe sobre a Língua Brasileira de Sinais-LIBRAS e dá outras providências. Publicada no Diário Oficial da União em 24/04/2002.

LODI, A. C. B. A leitura como espaço discursivo de construção de sentidos: oficinas com surdos. Tese de doutorado. Pontifícia Universidade Católica de São Paulo, 2004.

MAHER, T. M. O dizer do sujeito bilíngue: aportes da sociolinguística. In: FAVORITO, W.; GOMES, M. R.; LOUREIRO, V. R.; QUINTIERI, C. S. N. D.; RAMOS, M. I. B. B. (Orgs.). Anais do seminário desafios e possibilidades na educação bilíngue para surdos. Rio de Janeiro: Editora Líttera Maciel Ltda., 1997.

MORAIS, F. B. C. de. O gênero resumo: a compreensão escrita em contexto de sala de aula bilíngue. Arqueiro, v. 25, p. 28-38. Rio de Janeiro, 2013.

QUADROS, R. M. de. Ideias para ensinar português para alunos surdos - Brasília: MEC, SEESP, 2006.

RAMOS, R. C. G. Gêneros textuais: proposta de aplicação em cursos de língua estrangeira para fins específicos. The ESPecialist, 2004. v.24, n.2: 107-129.

SALLES, H. M. M. L. [et al.]. Ensino de língua portuguesa para surdos: caminhos para a prática pedagógica. Vol.2. Brasília: MEC, SEESP, 2004. p.96-117 


\title{
S Linguagens
}

ANEXO A - Unidade didática sobre o gênero textual receita

\author{
Fase 1: Apresentação \\ a-dia. Vejamos um exemplo: \\ $\underline{\text { Salada de tomate-cereja marinado }}$ \\ Ingredientes \\ 4 xícaras $(600 \mathrm{~g})$ de tomate-cereja cortado ao meio \\ $1 / 4$ xícara $(60 \mathrm{ml})$ de azeite \\ 3 colheres (sopa) de vinagre de cidra \\ 1 colher (chá) de salsa seca \\ 1 colher (chá) de manjericão seco \\ 1 colher (chá) de orégano \\ $1 / 2$ colher (chá) de sal \\ 1 1/2 colher (chá) de açúcar \\ Modo de preparo
}

Esta etapa deverá acontecer em LIBRAS, explorando a compreensão do aluno.

Nesta unidade trataremos do gênero receita, conhecido e utilizado por muitas pessoas no dia-

3. Em uma tigela pequena ou numa jarra de medida, prepare o molho misturando o azeite, o vinagre de cidra, as ervas, o sal e o açúcar.

4. Coloque o tomate-cereja numa travessa e regue-o com o molho. Misture com cuidado, deixando os tomates cobertos pelo molho. Mantenha a salada na geladeira por 2 horas, no mínimo.

Dica: Antes de servir, misture a salada de baixo para cima.

Preparo:10mins > Tempo adicional:2horas na geladeira > Pronto em:2horas10mins

Serve: 7 pessoas

Disponível em http://allrecipes.com.br/receita/2948/salada-de-tomate-cereja-marinado.aspx $(02 / 11 / 2016,16: 08)$

Perguntas para reflexão

a) Você já leu uma receita?

b) Para que ela serve?

c) Onde você já viu receitas escritas?

d) Quem costuma ler esse tipo de texto? E essa receita acima? Quem se interessaria por ela?

e) Você conhece alguma outra receita?

f) Na receita acima, você conhece todos os ingredientes usados?

g) Se não conhecer e quiser fazer a receita, como fará para descobrir que ingredientes são?

h)Todas as receitas precisam ir ao forno/fogão? Dê exemplos. 


\section{Linguagens \& Cidadania}

\section{Fase 2: Detalhamento}

Esta etapa deverá acontecer primeiramente em LIBRAS, explorando a compreensão do aluno

e, no segundo momento, com registro em Português.

Vejamos mais um texto do gênero receita:

BOLO DE CENOURA

INGREDIENTES

MASSA:

- $1 / 2$ xícara (chá) de óleo

- 3 cenouras médias raladas

- 4 ovos

- 2 xícaras (chá) de açúcar

- 2 e $1 / 2$ xícaras (chá) de farinha de trigo

- 1 colher (sopa) de fermento em pó

\section{COBERTURA:}

- 1 colher (sopa) de manteiga

- 3 colheres (sopa) de chocolate em pó

- 1 xícara (chá) de açúcar

\section{MODO DE PREPARO}

MASSA:

6. No liquidificador, bata primeiro a cenoura com os ovos e o óleo

7. Acrescente o açúcar e bata por mais 5 minutos

8. Em uma tigela ou na batedeira, adicione o restante dos ingredientes misturando tudo, menos o fermento

9. Acrescente o fermento e misture lentamente com uma colher

10. Asse em forno preaquecido $\left(180^{\circ} \mathrm{C}\right)$ por 40 minutos

\section{COBERTURA:}

3. Misture todos os ingredientes, leve ao fogo e misture até obter uma consistência cremosa.

4. Despeje a calda por cima do bolo.

PREPARO: 40 MIN

RENDIMENTO:8 PORÇÕES

Disponível em http://www.tudogostoso.com.br/receita/23-bolo-de-cenoura.html (02/11/2016, $17: 10)$

a) As receitas têm títulos. Para que eles servem? Qual é o título dessa receita?

b) Em uma receita, temos duas partes principais. Quais partes você observa na receita acima? 


\section{Linguagens \& Cidadania}

c) Compare essa receita com a primeira receita analisada nesta unidade. O que elas têm de semelhante? Marque no quadro abaixo:

\begin{tabular}{||l||l||l||}
\hline & Salada de Tomate-Cereja & Bolo de Cenoura \\
\hline Título & & \\
\hline Lista de ingredientes & & \\
\hline Dicas especiais & & \\
\hline $\begin{array}{l}\text { Quantidade de cada } \\
\text { ingrediente }\end{array}$ & & \\
\hline Modo de fazer & & \\
\hline Tempo de preparo & & \\
\hline Rendimento & & \\
\hline
\end{tabular}

d) Na parte "Modo de Fazer", das duas receitas, aparecem objetos e utensílios da cozinha. Liste-os:

e) No caso do objeto "travessa", que aparece na primeira receita, que outro sentido essa palavra pode ter, em outra situação? E as palavras "massa" e "cobertura"?

f) No "Modo de Fazer" das duas receitas aparecem verbos, como: bata, acrescente, misture, adicione, asse, prepare, coloque e mantenha. É comum, nas receitas, aparecerem verbos nessa forma. Estes verbos indicam:

( ) um fato que já aconteceu (pretérito perfeito)

( ) um fato que precisa ser feito (imperativo)

( ) um fato que será realizado (futuro do presente)

g) Complete o quadro dando a forma infinitiva dos verbos, como no modelo:

\begin{tabular}{||l||l||}
\hline Bata & Bater \\
\hline Acrescente & \\
\hline Misture & \\
\hline Adicione & \\
\hline \hline Asse & \\
\hline Prepare & \\
\hline Coloque & \\
\hline Mantenha & \\
\hline
\end{tabular}

h) Complete a receita abaixo com os verbos que estão entre parênteses usando a forma imperativa:

Brigadeiro 


\section{$\checkmark$ Linguagens}

Ingredientes

Rende: 40 brigadeiros pequenos

- 1 lata de leite condensado

- 1 colher (sopa) de manteiga

- 2 colheres (sopa) de chocolate em pó

- Chocolate granulado para decorar

Modo de preparo

Preparo:1hora > Pronto em:1hora

4. (despejar) o leite condensado numa panela média em fogo médio. (adicionar) a manteiga e o chocolate em seguida.

5. (manter) o fogo médio e (mexer) sempre até que o fundo da panela comece a aparecer. (retirar) do fogo, (despejar) o brigadeiro numa superfície untada $\mathrm{e}$ ( deixar) esfriar um pouco.

6. Quando o brigadeiro estiver morno, (enrolar) em pequenas bolas e (passar) no chocolate granulado. (colocar) os brigadeiros em forminhas antes de servir.

Disponível em http://allrecipes.com.br/receita/9542/brigadeiro-f-cil.aspx (20/11/2016, 18:26)

\section{Fase 3: Aplicação}

Nesta etapa, a prioridade é o registro escrito e a produção escrita individual do gênero proposto.

1. Pesquisar uma receita de sua preferência e trazê-la para sala de aula. Identificar suas partes, colorindo de diferentes cores, cada uma delas. Circular os verbos que estão no modo imperativo. (O trabalho poderá ser feito em grupo e utilizando o tempo da aula na sala de informática.) Haverá exposição dos trabalhos.

2. Escolha um prato que você sabe fazer. Pode ser bem simples, como um suco, om doce, uma salada, o que desejar. Escreva a receita completa.

3. Será organizado um livro de receitas da turma com o trabalho de cada aluno. 